\title{
Activity of fecal coliform bacteria measured by 4 -methylumbelliferyl- $\beta$-D-glucuronide substrate in the northern Adriatic Sea with special reference to marine snow
}

\author{
Gerald Müller-Niklas, Gerhard J. Herndl \\ Institute of Zoology, University of Vienna, Althanstr. 14, A-1090 Vienna, Austria
}

\begin{abstract}
Glucuronidase activity of fecal coliforms was measured with the fluorogenic substrate analog 4-methylumbelliferyl- $\beta$-D-glucuronide (MUG) in the northern Adriatic Sea during summer 1991 (1) to determine the distribution of MUG activity along a trophic gradient from oligotrophic waters to the eutrophic waters near the mouth of the Po River, and (2) to evaluate the role of marine snow as a scavenging agent of fecal coliforms in coastal waters. Along the trophic gradient, MUG activity was lowest in the most offshore central part of the northern Adriatic and increased towards the coastal stations by a factor of 2. MUG activity integrated over the entire water column increased almost 10 -fold from May to August. Highest activity was generally detectable in the surface layers and declined with depth. MUG activity in marine snow was found to be up to 100 times higher than in ambient water and therefore corresponded with enrichment factors calculated for other auto- and heterotrophic microorganisms. Similarly to actively growing microbial communities, an exponential increase in MUG activity in marine snow was detectable. Based on these findings we conclude that fecal coliforms in marine snow have higher survival rates accompanied by higher activity (measured here as MUG activity) than in the ambient water.
\end{abstract}

Fecal coliform bacteria are characterized by a specific enzyme which makes them distinguishable from other members of the bacterial community in aquatic systems on the basis of their enzymatic activity (Berg \& Fiksdal 1988, Clark et al. 1991). Measurement of glucuronidase activity of fecal coliforms has been compared recently with the traditional membrane filtration fecal coliform (MFC) technique (Clark et al. 1991). Based on the experiments performed by these authors, glucuronidase activity as determined by specific substrate analogs corresponds well with the MFC technique if there are $>10$ colony-forming units (CFU) of Escherichia coli $100 \mathrm{ml}^{-1}$ (Clark et al. 1991). Thus, the use of fluorescent substrate analogs to esti- mate the abundance of fecal coliforms might be a powerful tool for rapidly evaluating the influence of fecal coliform contamination of nearshore waters.

In the Adriatic Sea, counterclockwise currents isolate the northern water masses from the remaining Adriatic waters at the onset of summer stratification (Orlic 1987). Concurrently with this - at least partial isolation of the water masses, human populations living along the coasts increase by about 2 orders of magnitude during summer months. In nearshore, coastal waters this situation might lead locally to elevated fecal coliform concentrations (Fuks 1980). Another pecularity of the northern Adriatic which is probably directly linked to the above-mentioned current pattern during summer is the development of marine snow and large marine clouds (Herndl \& Peduzzi 1988, Stachowitsch et al. 1990, Herndl et al. in press). These amorphous aggregates have been shown to efficiently scavenge particles from the water column (Puskaric et al. 1992), leading to biomass accumulation in confined environments (marine snow) while concurrently depleting the ambient water of planktonic organisms (Herndl in press).

The purpose of this study was 2-fold. Firstly, we wanted to determine the glucuronidase activity along a trophic gradient across the northern Adriatic Sea from the oligotrophic eastern part to the highly eutrophic western part off the Po River estuary during summer. We hypothesized that glucuronidase activity in the central parts of the northern Adriatic Sea would be undetectable as fecal coliform bacteria decay during transport from the coast. Secondly, we attempted to evaluate the role of marine snow as a scavenging agent for fecal coliforms. Sampling on a 
narrow temporal scale, we followed the development of glucuronidase activity in marine snow and ambient water by selectively collecting these amorphous aggregates. As has also been shown for other organisms (Bochdansky \& Herndl 1992a, b, Kaltenböck \& Herndl 1992), we expected higher glucuronidase activity in marine snow as compared to ambient water.

The study was carried out in the northern Adriatic Sea during summer 1991. Samples were collected on 3 cruises of the RV 'Vila Velebita' along a trophic gradient starting off Rovinj (Croatia) to the mouth of the Po River (Fig. 1, route 1) between May and September; on one occasion we also sampled along the more oligotrophic Istrian peninsula (Fig. 1, route 2). At each station samples were taken from $0.5,5,10$ and $20 \mathrm{~m}$ depth. Additionally, marine snow and ambient water samples were collected by SCUBA divers ca $1.5 \mathrm{~km}$ off the Laboratorio di Biologia Marina di Trieste-Aurisina (Italy) in the Gulf of Trieste. (For a detailed description of the sampling procedure consult Herndl 1988.) Briefly, marine snow was collected using $60 \mathrm{ml}$ disposable syringes rinsed with ambient water prior to sampling. As marine snow aggregates were at least $0.5 \mathrm{~cm}$ in length and quite numerous (see also Herndl in press) it was possible to collect them without including the surrounding water. Ambient water was collected with hand-made $870 \mathrm{ml}$ syringes. Care was taken not to include visible aggregates in the ambient water sample. During the cruises the samples were analysed on board the ship while marine snow and ambient water samples collected by SCUBA divers were brought back to

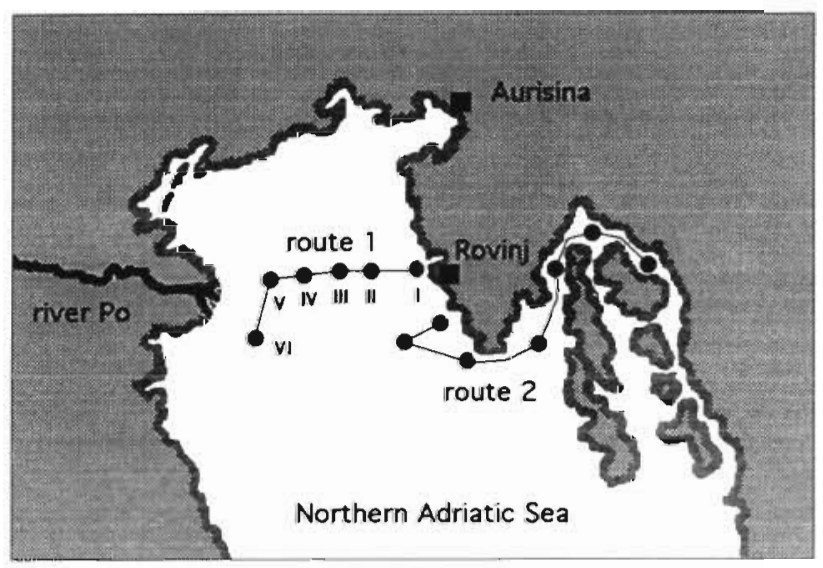

Fig. 1. Study location in the northern Adriatic Sea. Water samples were taken along the trophic gradient from Rovinj (Croatia) to the entrance of the Po River (Italy) (route 1) at 4 depths $(0.5,5,10$ and $20 \mathrm{~m})$ at the stations indicated by circles; in July we also sampled along the Istrian Peninsula (route 2). Marine snow and ambient water were collected by SCUBA divers about $1.5 \mathrm{~km}$ off the Laboratorio di Biologia Marina di Aurisina the shore-based laboratory. Generally, processing of samples began within $20 \mathrm{~min}$ after collecting the material.

To determine glucuronidase activity, 4-methylumbelliferyl- $\beta$-D-glucuronide (MUG; Sigma Chemicals) was used as substrate. The increase in fluorescence over time (incubation period was usually less than $60 \mathrm{~min}$ ) was measured with a Jasco 820 -FP spectrofluorometer at in situ temperature. The increase in fluorescence over time was calibrated with known amounts of methylumbelliferone (Sigma Chemicals) and assuming a linear increase in fluorescence over a wide range of substrate released. This assumption had been verified in preliminary experiments (data not shown). We used the tracer approach rather than saturation kinetics to evaluate the actual activity of glucuronidase in the sea. A more detailed description on the differences between the 2 approaches (tracer vs kinetic studies) will be given elsewhere. In this study we used $2.5 \mu \mathrm{M}$ final concentration of MUG.

As shown in Fig. 2, MUG activity increased from May to early September by about 1 order of magnitude, with highest MUG activity generally found in the surface waters (Fig. 2). Only in August was higher MUG activity detectable in the $5 \mathrm{~m}$ depth horizon. Integrating MUG activity over several depth horizons revealed an increase in activity towards the Po River after an initial decline from the coastal station in front of Rovinj towards the oligotrophic Stn II (Fig. 3). The increase from the most oligotrophic station to the station in front of the Po River (Stn V) was generally less than 2 -fold. This is a rather small increase considering the rapid decline of MUG activity with depth and time (Fig. 2). As shown in Fig. 1, Stn VI is about

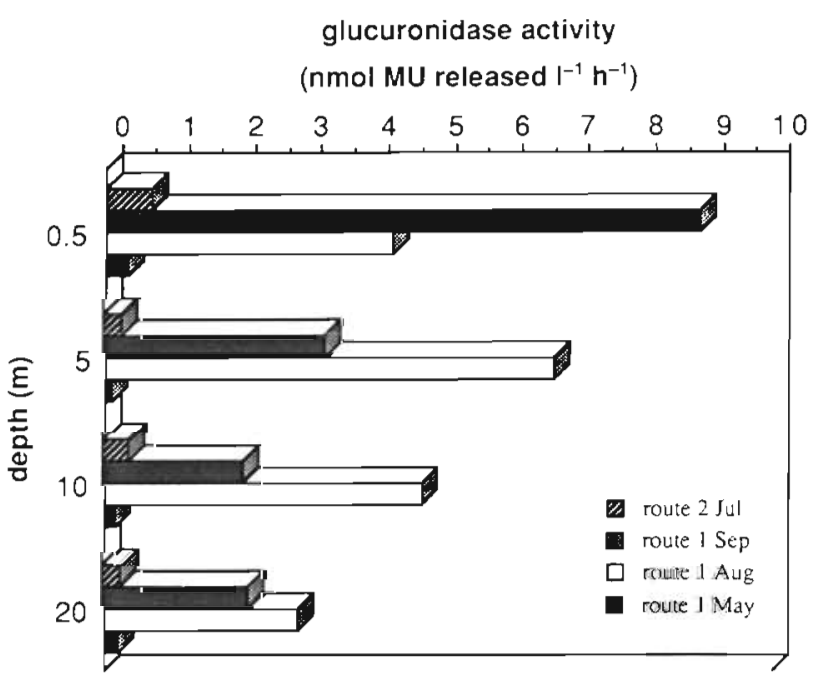

Fig. 2. Distribution of MUG activity in nmol methylumbelliferone (MU) released $\mathrm{l}$ ' $\mathrm{h}^{-1}$ at different depths and sampling dates 


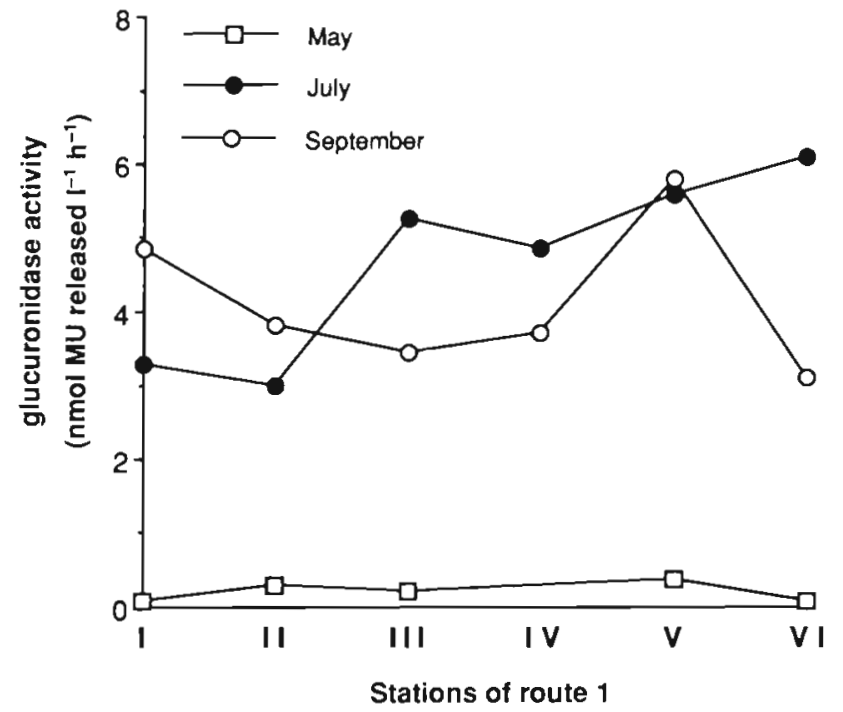

Fig. 3. Differences in MUG activity along a trophic gradient and among different months. Oligotrophic waters come from the southern Adriatic along the eastern coast (Stn I), and eutrophic waters at the western coast of the northern Adriatic are mainly caused by the influx from the Po River (Stn V). See Fig. 1 for location of sampling sites. Data points represent the integrated mean of 4 depths

$20 \mathrm{~km}$ south of the entrance of the Po River. Since the water masses of the Po River are transported southward the decrease in MUG activity at this station most likely reflects dilution of the water masses with more oligotrophic waters originating from the central parts of the northern Adriatic Sea.

In the northernmost part of the Adriatic Sea - the Gulf of Trieste - we followed the development of MUG activity in marine snow and ambient water. While MUG-activity in ambient water increased only slightly from early June (Julian Day 150) to mid-July (Julian Day 190) and declined slightly again thereafter, MUG activity in marine snow increased exponentially with time from early June to mid-August (Julian Day 210) (Fig. 4). By mid-August, MUG activity in marine snow was about 100 times higher than in ambient water.

In this paper we determined the activity of glucuronidase by a fluorogenic substrate analog in natural waters. As glucuronidase is expressed exclusively by fecal coliform bacteria the measurement of this enzymatic activity should be directly related to the density of fecal coliforms in the water. Recently, Clark et al. (1991) and Rice et al. (1991) have correlated MUG activity with CFU counts of fecal coliforms. These authors found good correlations between measurement of MUG activity and the MFC method at fecal coliform concentrations $>10 \mathrm{CFU} 100 \mathrm{ml}^{-1}$. A potential problem, however, is the occasionally false negative response when MUG activity is assessed (Clark et al.

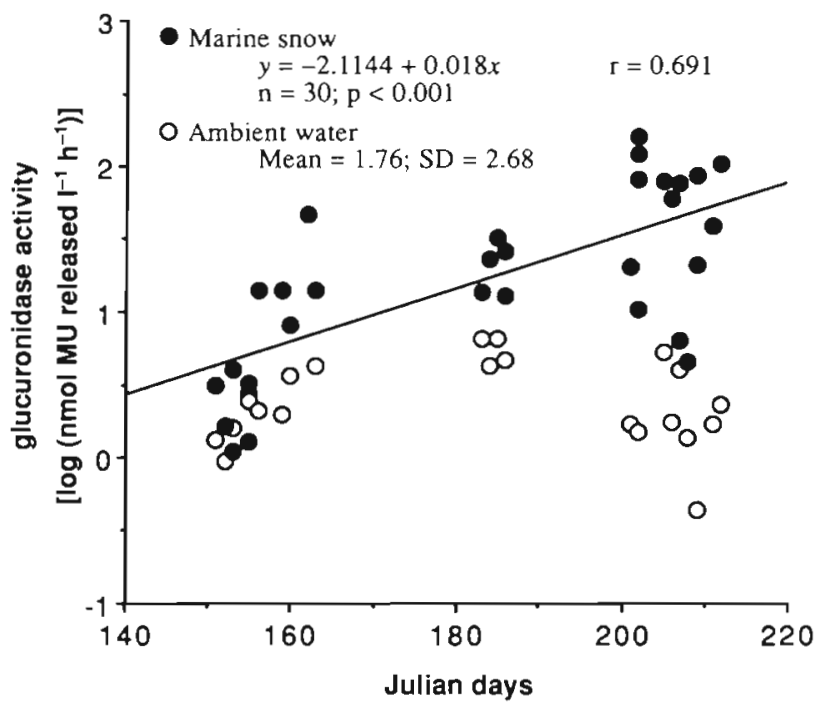

Fig. 4. Development of MUG activity in marine snow and ambient water during summer 1991 in the Gulf of Trieste

1991). The reason for these false negative responses remains speculative; substrate specificity, however, might be one of the possible causes (Clark et al. 1991). Despite these as yet unsolved problems in the determination of MUG activity, we feel that our data reflect actual fecal coliform activity in natural waters since fecal coliform concentrations in the investigation area are higher than $10 \mathrm{CFU} 100 \mathrm{ml}^{-1}$ (Wachs 1969), which has been determined to be the lower limit yielding good agreement between MUG activity and the MFC method (Clark et al. 1991).

MUG activity increased by ca 1 order of magnitude from May to August, whereas fecal coliforms generally decrease (in terms of CFU) with increasing temperature in the marine environment (Berg \& Fiksdal 1988, Brettar \& Höfle 1992). The increase in enzyme activity is probably due to its temperature dependency, as has been reported by numerous authors (see Chrost 1991 for a review). MUG activity varied only by a factor of 2 along the transect from the oligotrophic eastern part to the eutrophic western part of the northern Adriatic Sea. On both sides of the northern Adriatic Sea the stations near the coast (Stn I and Stn V) exhibited slightly higher MUG activity than the more offshore stations (Stns II and VI). The influence of the Po River is manifested in elevated MUG activities detectable at the stations in front of the river outflow (Stns $V$ and IV). The rather low variation in activity along the transect does not correspond, however, with previous reports on the rapid decline in fecal coliform CFU with distance from the shore. Wachs (1969) and Fuks (1980) detected a decline in CFU by almost 3 orders of magnitude along a transect of $1600 \mathrm{~m}$ from the shore towards 
the open Adriatic. This discrepancy might be due to a loss of culturability of fecal coliforms, as shown for Escherichia coli (Martinez et al. 1989): these authors studied mortality of $E$. coli in the sea and found that the bacteria lost their culturability before metabolic activity ceased and cell lysis started. Thus it is likely that the slight reduction in MUG activity that we found in the central part of the northern Adriatic reflects persisting enzymatic activity of fecal coliforms; the presence of these coliforms would not have been detectable using the MFC method.

Marine snow has been shown to be enriched in several nutrients as well as in autotrophic and microheterotrophic biomass (Alldredge \& Silver 1988, Alldredge \& Gotschalk 1990, Herndl in press). In the northern Adriatic Sea, marine snow occasionally increases in size to form clouds of several meters length (Stachowitsch et al. 1990). As shown for the autotrophic component by Kaltenböck \& Herndl (1992) and for zooplankton (Bochdansky \& Herndl 1992a) planktonic organisms are efficiently trapped by marine snow. In a subsequent paper we will show that dissolved organic matter (DOM) and heterotrophic bacteria also follow this trend. As the mucoid matrix of marine snow and the occasionally resulting mucilage are a peculiar environment with high nutrient concentrations and reduced shear forces, survival of fecal coliforms might be different from that in the bulk seawater. Lopez-Torres et al. (1988) emphasized that the survival rates of Escherichia coli increase with increasing nutrient concentrations. From Fig. 4 it is evident that MUG activity increased exponentially in marine snow during summer. Similar exponential increases have also been detected in heterotrophic bacteria and associated extracellular enzymatic activity (MüllerNiklas \& Herndl unpubl.). While for heterotrophic bacteria this exponential increase might be caused by adhesion of free-living bacteria to the sticky matrix of the mucoid aggregates and a concurrent division and growth of bacterial cells already attached to the mucoid matrix, the exponential increase in MUG activity in mucoid aggregates should not be caused by growth of fecal coliforms since survival of fecal coliforms, in the marine environment is rather limited (Berg \& Fiksdal 1988, Brettar \& Höfle 1992).

Based on this finding one would expect either a constant rate of MUG activity in marine snow over time or a linear increase if survival rates are higher in marine snow than in ambient water, rather than an exponential increase. Considering for the moment only mucoid aggregates, 2 possible explanations for the observed pattern can be put forward: either the scavenging efficiency, or the potential scavenging surface, increases exponentially with time. Although we do not have data on changes in stickiness of the mucoid aggregates, it seems unlikely that scavenging efficiency increased exponentially over time. Rather, we assume that stickiness decreases with age of the mucoid aggregate, since more refractory particulate material dominates the matrix of older mucoid aggregates while the colloidal material is typical for young marine snow (Herndl in press, Müller-Niklas \& Herndl unpubl.). Also, there is no evidence which leads us to suspect that the effective scavenging surface of the mucoid matter increased exponentially during the investigation period. On the contrary, we observed a decrease in numbers of marine snow particles accompanied by an increase in volume of single marine snow particles. Thus the surface: volume ratio decreased rather than increased (as one would predict for an increasing scavenging surface). We may conclude, therefore, that it is unlikely that changes in the mucoid matter caused the observed exponential increase in MUG activity. Considering now whether changes in the activity of fecal coliforms cause the exponential increase in MUG activity of marine snow, we might speculate that the survival rates would increase as grazing pressure of bacterivorous protists in marine particles is reduced (Caron 1987). Recently, Gonzalez et al. (1992) found that the dominant factor causing elimination of Escherichia coli in seawater is size-selective grazing by bacterivorous flagellates. Additionally, it has been demonstrated that high nutrient concentrations increase survival rates of $E$. coli (Lopez-Torres et al. 1988). Based on these findings we assume that survival rates and metabolic activities of fecal coliforms are significantly enhanced as soon as they become attached and embedded in marine snow. Enrichment factors for MUG activity are comparable with those for other extracellular enzymatic activities, such as glucosidase and amino-peptidase activity of heterotrophic bacteria as well as phosphatase activity of marine-snow-attached phytoplankton (Kaltenböck \& Herndl 1992, Herndl in press, Müller-Niklas \& Herndl unpubl.). Heterotrophic bacteria as well as phytoplankton remain active after becoming entrapped in marine snow and exhibit similar growth rates to those of their free-living counterparts (Kaltenböck \& Herndl 1992 . Herndl in press, Müller-Niklas \& Herndl unpubl.). Both organisms heterotrophic bacteria and phytoplankton showed an exponential increase in numbers and biomass in marine snow. We therefore hypothesize that fecal coliforms also remain active and dividing in marine snow, at least for a certain period of time.

In conclusion, we have shown that MUG activity along a trophic gradient in the northern Adriatic Sea varies only by a factor of 2 from coastal zones towards the oligotrophic central parts. Although highest activity was detectable in the surface layers, high activity was occasionally recorded for subpycnocline layers as well. The relatively high MUG activity in the 
central part of the northern Adriatic Sea as well as the exponential increase in activity in marine snow point to the fact that fecal coliform activity might remain detectable for periods longer than culture techniques reveal. The conspicuous amorphous aggregates in the northern Adriatic Sea concentrate fecal coliforms at approximately the same rates as other micro- and nanoplankton. As other nanoplankton communities have been shown to be highly active when embedded in the mucoid matrix, and thus their abundance and biomass shown to increase exponentially in marine snow during summer, we tentatively suggest that fecal coliforms also remain active in marine snow. The duration of this active period in marine snow is unknown at present; however, research is underway to elucidate this phenomenon.

Acknowledgements. We thank the colleagues of our department for invaluable help during field work as well as the staffs of the Institute 'Ruder Boskovic' Center for Marine Research at Rovinj, Croatia, and the Laboratorio di Biologia Marina di Trieste-Aurisina, Italy. This study was supported by the Austrian Science Foundation (FWF\# 7748 to G.J.H.) and the Osservatorio Alto Adriatico as part of a research program on the 'Reasons and Consequences of the Occurrence of Gelatinous Aggregations in the Northern Adriatic Sea'. The work is in partial fulfillment of the requirements towards a M.Sc. degree at the University of Vienna by G.M. -N

\section{LITERATURE CITED}

Alldredge, A. L., Gotschalk, C. C. (1990). The relative contribution of marine snow of different origins to biological processes in coastal waters. Cont. Shelf Res. 10:41-58

Alldredge, A. L., Silver, M. W. (1988). Characteristics, dynamics and significance of marine snow. Prog. Oceanogr. 20: $41-82$

Berg, J. D., Fiksdal, L. (1988). Rapid detection of total and fecal coliforms in water by enzymatic hydrolysis of 4 methylumbelliferone- $\beta$-D-galactosidase. Appl. environ. Microbiol. 54: 2118-2122

Bochdansky, A. B., Herndl, G. J (1992a). Ecology of amorphous aggregations (marine snow) in the Northern Adriatic Sea. III. Zooplankton interactions with marine snow. Mar. Ecol. Prog. Ser. 87: 135-146

Bochdansky, A. B., Herndl, G. I. (1992b). Ecology of amorphous aggregations (marine snow) in the Northern Adriatic Sea. V. Role of fecal pellets in marine snow. Mar. Ecol. Prog. Ser. 89: 297-303

Brettar, I., Höfle, M. G. (1992). Influence of ecosystematic factors on survival of Escherichia coli after large-scale release into lake water mesocosms. Appl. environ. Microbiol. 58: 2201-2210

This note was submitted to the editor
Caron, D. A. (1987). Grazing of attached bacteria by heterotrophic microflagellates. Microb. Ecol. 13: 203-218

Chrost, R. J. (1991). Microbial enzymes in aquatic environments. Springer Verlag, New York

Clark, D. L., Milner, B. B., Stewart, M. H., Wolfe, R. L., Olson, B. H. (1991). Comparative study of commercial 4-methylumbelliferyl- $\beta$-D-glucuronide preparations with the Standard Methods membrane filtration fecal coliform test for detection of Escherichia coli in water samples. Appl environ. Microbiol. 57: 1528-1534

Fuks, D. (1980). A study on the bacteriological pollution of the Northern Adriatic Sea coastal waters off Rovinj, Yugoslavia. Journées Étud. Pollutions. Commission Internationale pour l'exploration Scientifique de la Mer Mediterranée, Cagliari, p. 229-234

Gonzalez, J. M., Iriberri, J., Egea, L., Barcina, I. (1992) Characterization of culturability, protistan grazing, and death of enteric bacteria in aquatic ecosystems. Appl. environ. Microbiol 58: 998-1004

Herndl, G. J. (1988). Ecology of amorphous aggregations (marine snow) in the Northern Adriatic Sea. Il. Microbial density and activity in marine snow and its implication to overall pelagic processes. Mar. Ecol. Prog. Ser. 48: 265-275

Herndl, G. J. (in press). Marine snow in the northern Adriatic Sea: possible causes and consequences for a shallow ecosystem. Mar. microb. Food Webs

Herndl, G. J., Karner, M., Peduzzi, P. (in press). Floating mucilage in the northern Adriatic Sea: the potential of a microbial ecological approach to solve the 'mystery' Sci. Total Environ

Herndl, G. J., Peduzzi, P. (1988). Ecology of amorphous aggregations (marine snow) in the northern Adriatic Sea: 1. General considerations. P.S.Z.N. 1: Mar. Ecol. 9; 79-90

Kaltenböck, E., Herndl, G. J. (1992). Ecology of amorphous aggregations (marine snow) in the Northern Adriatic Sea. IV. Dissolved nutrients and the autotrophic community associated with marine snow. Mar. Ecol. Prog. Ser. 87: 147-159

Lopez-Torres, A. J., Prieto, L., Hazen, T C. (1988). Comparison of the in situ survival and activity of Klebsiella pneumoniae and Escherichia coli in tropical marine environments. Microb. Ecol. 15: 41-47

Martinez, J, Garcia-Lara, J., Vives-Rego, J. (1989). Estimation of Escherichia coli mortality in seawater by the decrease in ${ }^{3} \mathrm{H}$-label and electron transport system activity Microb. Ecol. 17: 219-225

Orlic, M. (1987). Oscillations of the inertia period on the Adriatic Sea shelf. Cont. Shelf Res. 7: 577-598

Puskaric, S., Fowler, S. W., Miquel, J C. (1992). Temporal changes in particulate flux in the northern Adriatic Sea Estuar. coast. Shelf Sci. 35: 267-287

Rice, E. W., Allen, M. J., Brenner, D. J., Edberg, S. C. (1991) Assay for $\beta$-glucuronidase in species of the genus Escherichia and its applications for drinking-water analysis. Appl. environ. Microbiol. 57: 592-593

Stachowitsch, M., Fanuko, N., Richter, M. (1990). Mucus aggregates in the Adriatic Sea: an overview of stages and occurrences. P.S.Z.N. 1: Mar. Ecol. 11:327-350

Wachs, B. (1969). Probleme der bakteriellen Verschmutzung küstennaher Meeresgebiete. Wass. Abwass. Forsch. 3: 1-10

Manuscript first received: August 31, 1992

Revised version accepted: October 27, 1992 